\title{
Controlling autonomous scalar discrete dynamical systems generated by non self Lipschitzian functions
}

\author{
VASILE BERINDE ${ }^{1,2}$ and GABRIELla KOvÁcs ${ }^{1}$
}

\section{ABSTRACT.}

We apply fixed point techniques of Krasnoselskij type for stabilizing autonomous scalar discrete dynamical systems in the case of Lipschitzian functions.

Acknowledgements. The research was supported by the Grants PN-II-RU-TE-2011-3-239 and PN-II-ID-PCE-2011-30087 of the Romanian Ministry of Education and Research.

\section{REFERENCES}

[1] Bair, J. and Haesbroeck, G., Monotonous stability for neutral fixed points, Bull. Belg. Math. Soc., 4 (1997), 639-646

[2] Berinde, V., Iterative approximation of fixed points, Second edition, Springer-Verlag, Berlin, Heidelberg, New York, 2007

[3] Berinde, V. and Kovács, G., Stabilizing discrete dynamical systems by monotone Krasnoselskij type iterative schemes, Creat. Math. Inform., 17 (2008), No. 3, 298-307

[4] Berinde V. and Păcurar, Mădălina, Controlling chaotic discrete dynamical systems through fixed point iterative methods, in PAMM, Special Issue: 79th Annual Meeting of the International Association of Applied Mathematics and Mechanics (GAMM), Bremen 2008, Vol. 8, Issue 1, Pages 10877-10878; DOI: 10.1002/pamm.200810877

[5] Devaney, R. L., An Introduction to Chaotic Dynamical Systems, Second Ed., Addison-Wesley Publ. Comp., 1989

[6] Hillam, B. P., A generalization of Krasnoselski's theorem on the real line, Math. Magazine, 48 (1975), 167-168

[7] Holmgren, R. A., A first course in discrete dynamical systems, Second Ed., Springer-Verlag, Berlin, Heidelberg, New York, 2000

[8] Huang, W., Controlling Chaos Through Growth Rate Adjustment, Discrete Dyn. Nat. Soc., 7 (2002), No. 3, 191-199

[9] Kovács, Gabriella, On the convergence of a sequence, Bul. Ştiinţ. Univ. Baia Mare Ser. B Fasc. Mat.-Inform., 8 (1992), 53-62

[10] Yuan, Z. L., Xu, Z. Y. and Guo, L. X., Generalized synchronization of two bidirectionally coupled discrete dynamical systems, Commun. Nonlinear Sci. Numer. Simul., 17 (2012), No. 2, 992-1002

[11] Wang, L. S. and Xu, Z. B., Quantitative Studies on Asymptotic Growth Behaviors of Trajectories of Nonlinear Discrete Dynamical Systems, IEEE Trans. Automatic Control, 59 (2014), No. 7, 1930-1935

1 Department of Mathematics and Computer Science North University Center at Baia Mare

TECHNICAL UNIVERSITY OF CLUJ-NAPOCA

Victoriei 76, 430122 BAia MARE ROMANiA

E-mail address: vberinde@ubm.ro; kovacsgabriella@yahoo.com

2 Department of Mathematics and Statistics

King Fahd University of Petroleum and Minerals

DHAHRAN, SAUDI ARABIA

E-mail address: vasile.berinde@gmail.com

Received: 15.08.2010; In revised form: 23.08.2011; Accepted: 25.08.2014.

2010 Mathematics Subject Classification. 37C25; 47H10, 47J25.

Key words and phrases. Discrete dynamical system, fixed point attracting from below (from above), Lipschitz continuity, generalized Krasnoselskij type iteration. 